\title{
PATENCY OF THE DUCTUS ARTERIOSUS IN THE NEWBORN CALF AND FOAL
}

\author{
BY \\ E. C. AMOROSO, G. S. DAWES, AND JOAN C. MOTT \\ From the Nuffield Institute for Medical Research, University of Oxford \\ Received June 22, 1957
}

In the lamb, the ductus arteriosus does not close immediately after birth, but the direction of blood flow through it reverses. In the newborn lamb, therefore, blood normally flows from the aorta, through the ductus arteriosus, to the lungs (Born et al., 1955c; Dawes et al., $1955 a$ and $b$ ). Observations in newborn puppies (Handler, 1956) and babies (James and Rowe, 1957; Adams and Lind, 1957) indicate that in these species the course of the circulation is similar to that in newborn lambs. The present paper describes experiments that show the same train of events in two further species, the newborn calf and foal.

\section{METHODS}

One foal and three calves were examined in the field by direct auscultation and by phonocardiography. Two further foals and three calves were brought to the laboratory within six hours of birth, and phonocardiographic records were made before light anæsthesia was induced with intravenous sodium pentobarbitone. Two of the calves developed laryngeal spasm after the injection and a tracheal cannula was therefore inserted as soon as possible. The methods used were similar to those described previously (Dawes et al., $1955 a$ and $b$ ). Artificial positive pressure ventilation was provided by a Starling Ideal pump and access to the ductus arteriosus was obtained by removing the third and fourth ribs on the left side. Systemic arterial blood pressure was recorded from the descending aorta or from a carotid, femoral, or tarsal artery and pulmonary arterial pressure from a branch supplying the apex of the left lung. Blood samples were withdrawn simultaneously from the right ventricle (by direct puncture) and from catheters in the systemic and pulmonary arteries. The blood samples were analysed for their oxygen content and capacity as described previously (Born et al., 1955a).

\section{RESULTS}

Cardiac Murmurs in Unanasthetized Newborn Calves and Foals. Six calves were first examined seven minutes to four hours after birth. All exhibited a loud continuous murmur over the ductus arteriosus (Fig. 1b). This murmur had both a cardiac and respiratory variation. It was best heard in the interspace between the third and fourth ribs on the left side, well up in the left axilla. In order to apply the stethoscope bell effectively, it was found desirable to pull the left forelimb gently cephalad. The murmur radiated ventrally for as much as $6 \mathrm{~cm}$., along a narrow band between the third and fourth ribs. It was loudest within the first hour or so after birth and, in three calves, was no longer heard twelve hours later.

In some of the calves another murmur was also present, though for a shorter period of time. This was a presystolic murmur, heard at the apex and along the left side of the sternum (Fig. 1a), which could have been due to rapid flow through the mitral valve.

Three foals were also examined 7 to $7 \frac{1}{2}$ hours after birth, and all had a continuous loud murmur over the ductus arteriosus, localized to the same rib interspace, and very similar to that heard in calves (Fig. 2b). 


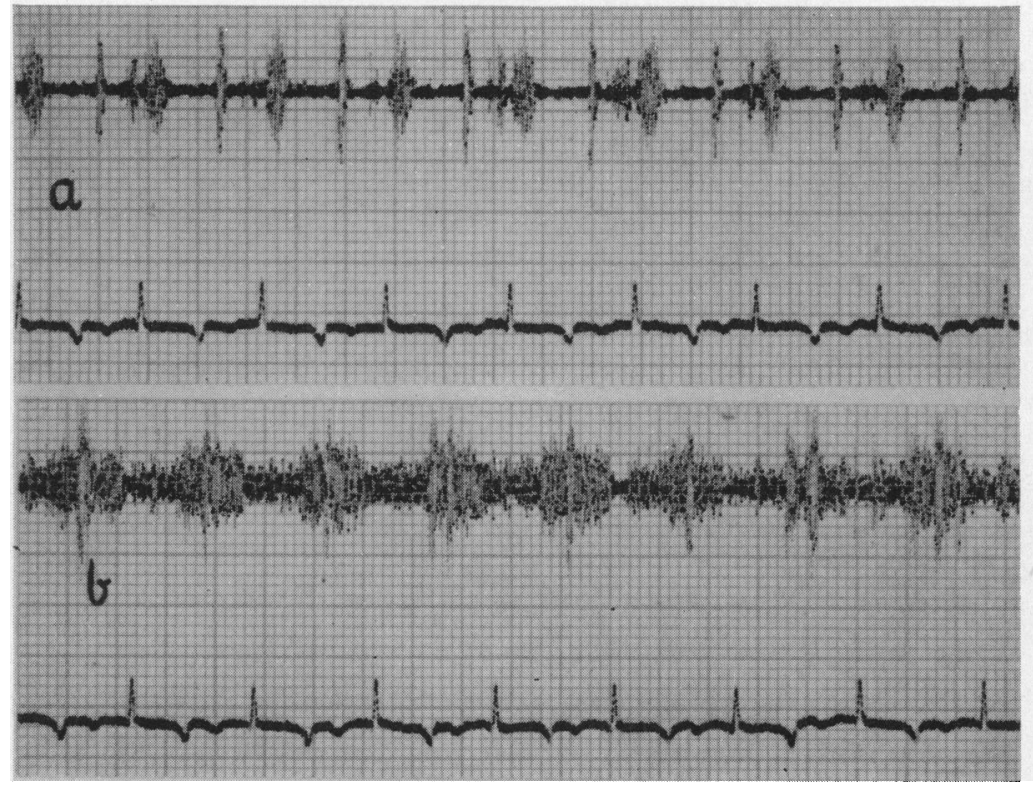

FIG. 1.-Calf, $4 \frac{1}{2}$ hours old, unanæsthetized. Records of phonocardiograph (above) and electrocardiograph (below). There is a presystolic murmur at the apex (a) and a loud continuous murmur over the ductus arteriosus (b).

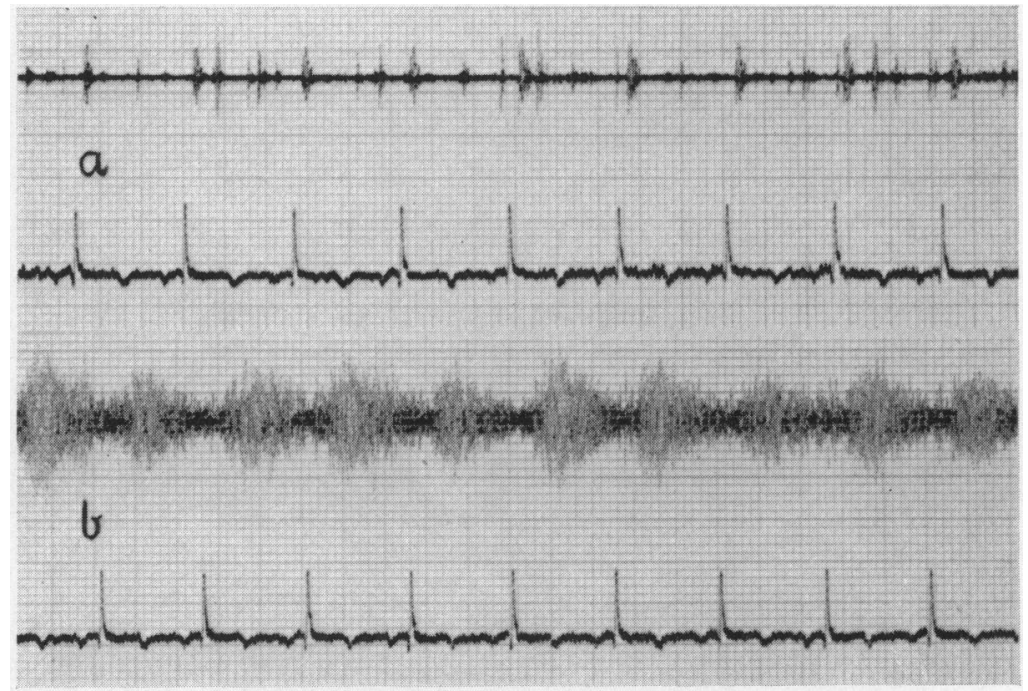

Fig. 2.-Foal, 7 hours old, unanæsthetized. Records of phonocardiograph (above) and electrocardiograph (below). There was no evidence of a murmur at the apex (a), but a loud continuous murmur was heard over the ductus arteriosus (b). 
Anasthetized Calves and Foals. The murmur heard between the third and fourth ribs on the left side of the chest persisted after the animals were lightly anæsthetized. When the chest was opened at this point the ductus arteriosus was found to lie immediately within the chest wall and did not give the impression of being greatly narrowed. The murmur sounded louder when the stethoscope bell was applied directly to the wall of the ductus; it radiated towards the pulmonary trunk, and was sometimes accompanied by a palpable thrill.

The ductus arteriosus was occluded for brief periods in three calves and two foals. This manœuvre invariably caused an increase in systemic arterial pressure and a fall of pulmonary arterial pressure (Fig. 3). The murmur and thrill from the ductus also disappeared on occlusion of the vessel (Fig. 4). These observations led to the conclusion that in the calf and foal, as in the lamb, blood flow persists through the ductus arteriosus from the aorta to the pulmonary trunk for some

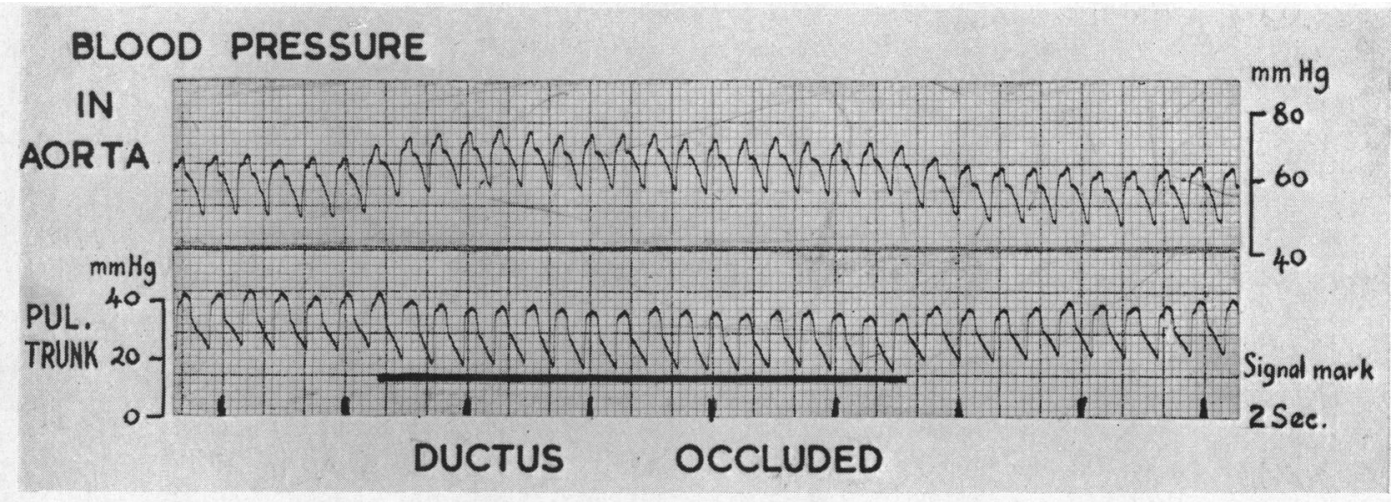

FIG. 3.-Calf, 6 hours old, pentobarbitone anæsthesia. Condenser manometer records of aortic pressure (above) and pulmonary trunk pressure (below). The ductus arteriosus was occluded during the signal mark. Time signal 2 seconds.

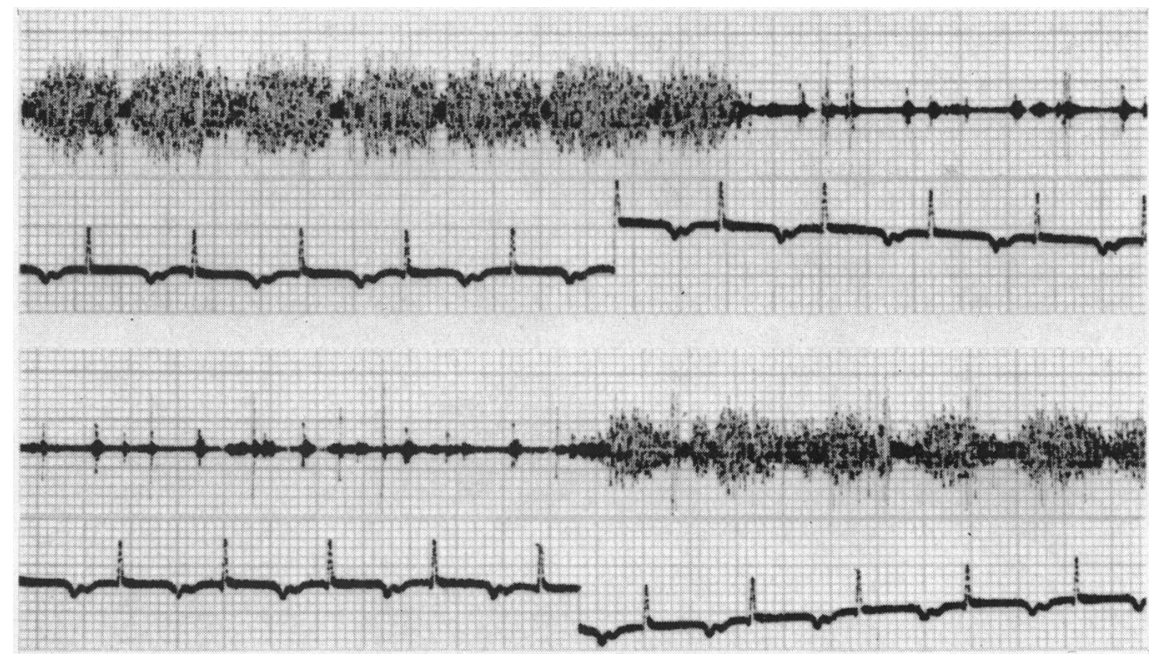

Fig. 4.-Calf, $5 \frac{1}{2}$ hours old, pentobarbitone anæsthesia. Phonocardiograph record from junction of ductus arteriosus and pulmonary trunk (above) and electrocardiogram (below). The two records are consecutive. The ductus arteriosus was occluded and released at the abrupt deflections $(=1 \mathrm{mv}$.) in the electrocardiographic record. 
hours after birth. This conclusion was confirmed by the analysis of blood samples taken simultaneously from the right ventricle, the pulmonary artery, and a systemic artery. Table I shows that some systemic blood always reached the pulmonary artery.

TABLE I

Percentage Oxygen Saturation of Blood in Newborn Calves and Foals

\begin{tabular}{l|c|c|c|c|c}
\hline & $\begin{array}{c}\text { Age } \\
\text { (hours) }\end{array}$ & $\begin{array}{c}\text { Systemic } \\
\text { artery }\end{array}$ & $\begin{array}{c}\text { Pulmonary } \\
\text { artery }\end{array}$ & $\begin{array}{c}\text { Right } \\
\text { ventricle }\end{array}$ & $\begin{array}{c}\text { Percentage of } \\
\text { aortic blood in } \\
\text { pulmonary artery }\end{array}$ \\
\hline Calf 2 & $8 \frac{1}{2}$ & $93 \cdot 5$ & 81 & $78 \cdot 5$ & 17 \\
\hline Calf 4 & 6 & 97 & 81 & 78 & 16 \\
\hline Calf 5 & 6 & 97 & $86 \cdot 5$ & 83 & 21 \\
\hline Foal 2 & $9 \frac{84}{2}$ & 94 & 84 & $79 \cdot 5$ & 26 \\
\hline Foal 3 & $8 \frac{74}{2}$ & 94 & 63 & 69 & 28 \\
\hline & 96 & 43 & 61 & 6 \\
\hline
\end{tabular}

Discussion

In the lamb, adequate ventilation of the lungs at birth so decreases the pulmonary vascular resistance as to cause the pulmonary arterial pressure to fall below the systemic pressure. The consequence is that blood flow through the ductus arteriosus reverses from the fætal (pulmonary trunk to aorta) to the neonatal (aorta to pulmonary trunk) direction (Born et al., 1955c). In addition, if the velocity of blood flow is sufficient, a continuous machinery murmur may be detected on auscultation. While the presence of such a murmur is, by itself, indicative of a patent ductus arteriosus, its absence does not necessarily imply that the ductus is closed (Dawes et al., 1955a). This type of murmur was readily detected in calves and foals as described in this paper, though even in these large animals the area over which the murmur was heard was not extensive.

The existence of a continuous murmur indicated patency of the ductus in the newborn calf and foal, and suggested that the direction of blood flow was from aorta to pulmonary artery, since in the lamb the murmur due to blood flow in the opposite direction is systolic in character (Dawes et al., 1955a). Direct evidence as to the direction of blood flow was obtained by observation of the effect of occlusion of the ductus on the systemic and pulmonary arterial pressures. When the blood was prevented from flowing through the ductus, the systemic pressure rose and the pulmonary arterial pressure fell. Moreover, the blood in the pulmonary artery contained more oxygen than that in the right ventricle, and the aortic blood contributed up to a quarter of the pulmonary blood flow. The course of the blood flow through the ductus arteriosus of calves and foals shortly after birth is therefore very similar to that seen in lambs. The proportion of pulmonary blood flow coming from the aorta in calves and foals was lower (3-28\%) than in lambs $(23-57 \%$ ) (Dawes et al., 1955b), but the calves and foals were several hours old, whereas the lambs' lungs had been ventilated for less than an hour.

James and Rowe (1957) and Adams and Lind (1957) have also found, by passing catheters, that the blood in the pulmonary artery of a newborn baby contains more oxygen than that in the right ventricle. On the other hand Eldridge et al. (1955) found more oxygen in samples of finger blood than of heel blood in young babies. While this observation is consistent with a patent ductus, it 
implies that blood is flowing through the ductus from pulmonary trunk to aorta. This could happen if the sampling procedure caused, indirectly, an increase of intrathoracic pressure and thereby reversed the normal direction of blood flow.

Angiographic records have also indicated that in both the newborn lamb and the puppy the ductus arteriosus is still open shortly after birth. Although contrast medium could be made to pass either way through the puppy's ductus, the pulmonary arterial pressure was less than the aortic, so that the direction of blood flow must normally be towards the lungs (Handler, 1956).

The murmur associated with the patent ductus of the newborn has now been heard in lambs, calves, and foals. More recently, Burnard (personal communication) has found cardiac murmurs in the majority of newborn babies, though the significance of these murmurs has yet to be established.

There is now evidence of various kinds that the ductus arteriosus remains patent for some time after birth in the following mammalian orders: primates (man), carnivores (dog), artiodactyls (sheep and cow), and perissodactyls (horse). It is clear that the blood flows from aorta to pulmonary trunk, and that conditions may be such as to cause a continuous murmur from the ductus. The benefit of an augmented pulmonary blood flow can be considerable if the lungs are not uniformly efficient as in the newborn (Born et al., 1955b). On the other hand failure of the ductus to close may impose a severe strain on the left heart, and inadequate ventilation of the lungs may cause a rise of pulmonary vascular resistance sufficient to reverse the direction of blood flow through the ductus. It is thus evident that the physiology of the neonatal circulation requires much further study in relation both to normal and pathological processes.

\section{SUMMARY}

A cardiac murmur, characteristic of blood flow through a patent ductus arteriosus, was heard in calves and foals within a short time after birth, and persisted for many hours.

Occlusion of the ductus arteriosus abolished this murmur and caused a rise of systemic arterial pressure and a fall of pulmonary arterial pressure.

The conclusion that the ductus arteriosus was patent, and that blood flowed from the aorta to the pulmonary artery, was supported by measurement of the oxygen content of blood withdrawn from the great vessels.

We wish to thank the Nuffield Foundation for their continued support, and Professor G. H. Acheson for helping with some of the experiments. We are most grateful to Mr. J. Elliott, Dr. J. A. Laing, Professor A. Messerry, and Mr. H. B. Parry for providing calves and foals.

\section{REFERENCES}

Adams, F. H., and Lind, J. (1957). Pediatrics, 19, 431.

Born, G. V. R., Dawes, G. S., and Mott, J. C. (1955a). J. Physiol., 130, 191.

,,-- , and Rennick, B. R. (1955b). J. Physiol., 130, 167.

Burnard, E. (personal communication).

Dawes, G. S., Mott, J. C., and Widdicombe, J. G. (1955a). J. Physiol., 128, 344.

-, (1955b). J. Physiol., 128, 361.

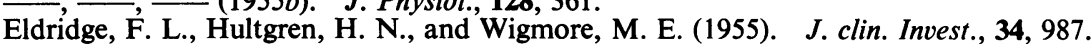

Handler, J. J. (1956). J. Physiol., 133, 202.

James, L. S., and Rowe, R. D. (1957). J. Pediatrics, 51, 1. 